\title{
o fazer-interpretativo de "os intocáveis"
}

\author{
Edith Lopes Modesto \\ Professora na Universidade Mackenzie
}

ABSTRACT: This article, methodologically supported by the French Semiotic Theory, tries to explain the kind of signifing object which The Untouchables is and how each person of the public seems to build a different discourse to him or herself.

KEY WORDS: Discursivization - Intertextuality - Irony - Veridiction.

\section{Introdução}

Assisti a Os Intocáveis, quando de seu lançamento nos cinemas, em companhia de uma amiga, como eu, amante da sétima arte. Qual não foi a nossa surpresa ao percebermos, durante a sessão, as reações passionais antagônicas que o filme desencadeava nos espectadores: enquanto ríamos muito, outros estavam tensos, nervosos, e alguns chegavam às lágrimas!

O público era diversificado quanto à faixa etária, mas nos pareceu que todos gostaram muito do filme (avaliação confirmada pelas críticas c tempo de exibição nos cinemas), inclusive minha amiga e eu.

O filme, de que se pode pressupor interpretações tão contraditórias e agrada a críticos, aficcionados e público em geral, despertou-me curiosidade. Desde esse dia, tenho assistido a Os Intocáveis, em vídeo e 
TV, tentando deslindar os artificios de que decorrem os resultados observados, sempre com o apoio do arcabouço teórico-metodológico da Semiótica de origem francesa, preocupada com a construção de modelos capazes de explicar situações e objetos significantes, no cómputo de urna teoria geral da significação.

\section{O Fazer-Interpretativo}

\section{A competen̂cia modal}

Basicamente, uní filme é um objeto significante construido que ó dado a assistir para sujeitos semioticamente competentes. Nesse caso, a nossa questão ć: qual o modo de existencia desse objeto significante para esses sujeitos - produtores/espectadores? - e, cm decorrência, qual a sua competen̂cia como sujeitos que interagem comunicativamente?

Em primeiro lugar, temos o objeto significante (filme), construido por sujeitos (equipe de produção), a que denominaremos texto fílmico. Em segundo lugar, temos o texto fílmico que é dado a assistir aos espectadores no cinema e se transforma em discurso.

Considerando o fazer do sujeito da enunciacão:

a) na dimensão pragmática do fazer-textual:

- o sujeito do fazer-filme (operador) realiza uma operação transformadora no nivel físico, produzindo Os Intocáveis;

- o sujeito do fazer-fílme (operador) realiza uma operação (enquanto um programa anterior de competência/performance) de realização de suas estruturas sêmio-narrativas atualizadas, na história de $O s$ Intocáveis, contada de modo cinematográfico.

b) na dimensão patêmico-cognitiva do fazer-discursivo:

- organização do saber e do fazer-saber: o sujeito do fazer-assistir/sujeito do assistir realizam programas de competência e manipulação que pertencem á instância da enunciação e, segundo proposta de PATTE 
(1986), implicam a realização sincrética de duas estruturas sêmio-narrativas atualizadas: a do enunciador e a do cnunciatário, implícitos, ambos dotados de competenĉia modal;

- organização do fazer-patêmico: sincretizado ao sujeito cognitivo, o sujeito-tímico realiza programas de competência e manipulação que pertencem à instância da enunciação e, segundo proposta de FONTANILLE (1986), implicam a realização de sua afetividade, a opacidade subjetiva do discurso, as escolhas avaliatórias.

O fazer-assistir ao filme, isto é, o discursivizá-lo, parte do sujeito da enunciação implícito c comporta as instâncias das duas posições actanciais: enunciador/enunciatário. O cnunciatário (simulacro do espectador), portanto, não c' apenas um destinatário, como o quercm as Teorias da Comunicação, mas um sujeito de fazer discursos, como o enunciador (simulacro dos produtores do filme), pois assistir ao filme é uní ato de significar (de linguagem), do mesmo modo que o ato de passar o filme.

No programa de manipulação, há um fazer-saber do enunciador, para um cnunciatário. Por isso mesmo, segundo Patte, suas competências semânticas não poderiam ser as mesmas, pois a manipulação seria inútil. Para que um contrato enunciativo c de veridicção (para urna troca cognitivo-pragmática) se já se possui o objeto-valor? Por outro lado, as competencias não poderiam ser completamente diferentes pois, impedindo a aceitação, pelo cnunciatário, das propostas contratuais que ele recebe, não poderiam ser realizadas no mesmo discurso.

Para ser aceito conjuntamente pelo enunciador/enunciatário, o discurso deve ser um contrato pelo qual a discursivizacão (enquanto manipulação) vise à transformação de estruturas ^ semio-narrativas atualizadas. Sc a transformação for drástica, o contrato que pressupõe o discurso proposto não será assumido. Em face dessa coerção, o enunciador realiza uma seleção de possibilidades, aceitando uma transformação de sua competência semântica, de modo a se adequar àquela do enunciatário.

significação 11/12 
Considerando os espectadores no cinema (simulacros do enunciatário): o ser-espectador já implica um espetáculo, onde se torna público uní texto/discurso social (considerado em Teoria da Comunicação do tipo Comunicação Dirigida, que contrasta com a Comunicação de Massa), como no teatro, em que a própria produção do discurso pressupõe a presença de um público (LANDOWSKI, 1992). Considerando a adequação coercitiva das competências dos actantes da enunciação, as realizações sincréticas das estruturas sêmio-narrativas serão diferentes para o mesmo texto filmico.

O mesmo conjunto significante, portanto, apresenta uma virtualidade de construções discursivas que, embora não-infinita, permite a realização de processos discursivos diferentes. E' como se cada espectador construísse um sentido do filme para si, ainda mais quando o discurso é pluriisotópico, como Os Intocáveis.

Esses processos discursivos, no entanto, são mediados por urna realidade empírica imánente que faz com que não possam diferir muito uns dos outros:

a) porque um só objeto semiótico possui uma só estrutura significante;

b) porque as competências dos actantes da enunciação não podem ser tão diversas, sob pena de o contrato não se estabelecer.

Sendo assim, podemos concluir:

a) o número possível de diferentes construções discursivas fica delimitado pelo conjunto significante realizado (parte de um sistema de coerções pelo dever-ser) e ele é a base de controle e avaliação da coerência do fazer interpretativo (processo virtual do saber-fazer);

b) para realizar toda a virtualidade interpretativa de um dado conjunto significante, teríamos que abarcar todas as formas de processos 
discursivos desencadeados por ele, nas suas diferentes interações com diferentes cnunciatários, ñas suas diversas formas de fazer cognitivo. A "verdade discursiva" seria então um jogo de intertextualidade impossível de se alcançar.

\section{A competência semântica}

Considerando Os Intocáveis, propomos que seja um objeto significante construido para que se realizem, a partir dele, processos discursivos muito simples e comuns, até complexos e originais, dependendo da competência semântica do sujeito da enunciação, pois algumas "leituras" possíveis do filme dependem de conhecimento específico anterior. conforme comentaremos abaixo:

a) argumento: a história ocorre em Chicago,em 1931, em plena "lei seca" Os Intocáveis são uma equipe selecionada de investigadores do governo, liderada por Eliot Ness, um jovem agente do Tesouro Nacional americano. Honestos, idealistas e corajosos, os protagonistas arriscam-se para acabar com o crime organizado que transforma a cidade em um campo de batalha comandado por Al Capone. No início sozinho. Eliot Ness conhece um experiente policial (Malonc) que lhe ensina a lidar com o submundo da máfia. Escolhem Stone, um jovem aspirante a policial. e Oscar, um agente federal que é contador. Dos quatro "intocáveis" morrem dois. mas afinal conseguem pôr Al Capone atrás das grades por sonegação de imposto de renda;

b) Os Intocáveis é explicitamente intertextual em relação á série homônima para TV da década de 50, em que o ator Robert Stack interpretava o personagem Eliot Ness;

c) a esse intertexto básico (com a série para TV), sobrepõe-se outro processo intertextual: 110 decorrer da narração. Os Intocáveis remete a vários "gêneros" fílmicos, através da intertextualidade com filmes famosos da história do cinema.

Entendemos, aqui, "género" como classes de discursos reconhe- 


\section{Edith Lopes Modesto}

cíveis graças a critérios de natureza "socioletaF (em oposição a "idioletaF - estilo) (GREIMAS e COURTÉS, s.d).

Em Os Intocáveis, trechos do filme (seqüências ${ }^{1}$ inteiras ou apenas cenas ${ }^{2}$ ) conformam-se a normas de um universo semântico relacionado à estratificaçào socioculturaf permitindo que reconheçamos:

a) gêneros: detetive; policial de ronda; cavalaria; western: de gángster; com gángster; suspense; romance; noir $\backslash$ comédia (?);

b) partes de outros filmes (intertextos explícitos/implícitos):

- O Encouraçado Potemkin (1925): abertura do filme e a seqüência da Estação; Outubro (1927): seqüência em que Al Capone mata um dos mafiosos com um taco de beisebol (Sergci Eiscnstein);

-- A Felicidade nào se Compra (1948): perfis análogos dos protagonistas principais (Frank Capra);

Janela Indiscreta (1955): seqüência da morte de Malone; Um Corpo que Cai (1959): a morte de Nitti (Alfred Hithcock);

- Os Corruptos (1954): perfis análogos entre Eliot Ness e Dave Bannion (Fritz Lang);

- Meu Ódio Será a tua Herança (1969); Sob o Domínio do Medo: principalmente, na câmera subjetiva c câmeras rápida c lenta exageradas, como na ponte EUA/Canadá; na morte dc Malone; morte de Nitti (Sam Pcckimpah);

\footnotetext{
1. Seqüência: divisão do ponto de vista do conteúdo que engloba um "plot" (literatura): inicio conllito solução do conllito (análogo a um Programa Narrativo, do Percurso Gerativo do Sentido). 2. Cena: divisão do ponto de vista de tempo e espaço (dia'noite: externa/interna). Em Semiótica, debreagens temporais eśpaciais.
} 
- Westerns, dc Scrgio Lconc: confronto na ponte c a trilha sonora de Ennio Morricone;

- Duble^ de Corpo (1984): a câmera subjetiva na seqüência do assassinato de Malone cita Hithcock em Janela Indiscreta e o próprio DePalma (Brian DePalma);

c) o denominado estilo Noir

- Malone é o termo neutro entre a polícia e os mafiosos. assim como um detetive noir é o termo neutro entre a polícia e os fora-da-lei. Como exemplo de sua "moral elástica" de detetive noit ele já tinha conhecimento de onde era o depósito dc bebida ilegal, o que teria evitado a humilhação de Eliot na cena da sombrinha ${ }^{3}$,

- há a espera de um testemunho que se deseja;

- Eliot Ness possui boa vontade, humanidade e uma evidente fraqueza que o tornam simpático, como os detetives noir;

- seqüências em tom azul pastel remetem ao contraste P\&B e enfatizam a contra-luz;

- o asfalto está sempre molhado, com poças d'água de depois da chuva;

- cidade grande dos EUA, espaços de passagem, maldcfinidos. como o depósito de bebidas, hal/s, escadas, pontilhões, bar enfumaçado, beco onde Malone briga com o policial gordo etc.,

- a nacionalidade italiana de Stone (no noir do lado do mal) e irlandesa de Malone (no noir do lado do bem);

3. Na primeira balida de Kliot Ness a um depósito, a caixa continha uma sombrinha ao invés de bebida ilegal. 


\section{Edith Lop es Modesto}

- uma certa clandestinidade (Stone tinha mudado de nome);

- Oscar Wallacc, o contador, é um personagem de aparência e caráter noir;

- Eliot Ness é humilhado (passa a mão no rosto, como em todos os momentos de alguma emoção), perde tudo, até seus espaços, como um detetive noir Por exemplo, na seqüência em que, derrotado, arruma seu escritório para ir embora etc.

\section{A intertextualidade}

A Teoria Semiótica entende a intertextualidade como "a possibilidade de transformação de sentido" (GREIMAS, 1970). Entretanto, ao conceito muito geral de que todos os textos mantêm entre si alguma relação intertextual, acrescenta-se, para maior especificidade, que, a partir do uso discursivo e estilístico, produzem-se formantes intertextuais, pressupondo um ato de intencionalidadc e uma estrutura actancial de discursivização.

A intertextualidade c' um processo de transcodificação que implica a instância do sujeito da enunciação c a transformação semântica de alguns valores virtuais do formante intertextual (RUPRECHT, 1986). como elemento diferencial em relação a outros textos, auxiliando o seu reconhecimento como intertexto. ao mesmo tempo que o homologa à totalidade do discurso em pauta.

O processo modalizador faz interagirem enunciador/enunciatário na produção do sentido intertextualizado, a partir dos seus dois contextos de crença e conhecimento (que são respectivamente sancionados):

a) o universo cognitivo de referência da instância das estruturas produtoras da intertextualidade. do ponto de vista do fazer-emissivo;

b) o universo cognitivo de referência da instância das estruturas interpretantes da intertextualidade, do ponto de vista do fazer-receptivo. 
Os formantes intertextuais apresentam-se, geralmente, sob forma figurativa $^{4}$ Em Os Intocáveis, figuras do plano do conteúdo, como a formação da polícia montada em plano superior ao da ponte da fronteira, antes do ataque; o chapéu que não cai da cabeça de Ness, mesmo quando ele passa por debaixo do carro (como se fosse diligência ou carroça dos filmes western) etc., ou, figuras do sistema semi-simbólico, como a cor rosada, o "plano-seqüência" (filmagem sem cortes) e a música romántica, quando da apresentação da casa de Eliot Ness, traços do plano da expressão que se homologam a traços do plano do conteúdo, como familia feliz, mulher e filha angelicais, o bem, enfim; em oposição à cor azulada, fúmaça, montagem (cortes), jazz, o molhado da rua, nas seqüências da morte da menina, ou quando Nitti ameaça a família de Ness, traços do plano da expressão que se homologam a traços de conteúdo de violência, chantagem, crime, o mal, enfim.

No filme, não há nenhum dispositivo de informação explícita sobre o processo intertextual por parte dos sujeitos do enunciado, em nivel de verbalização. Nesse caso, dependendo da competência epistêmica anterior, o fazer-interpretativo pode atribuir ao discurso um estatuto veridictório que vai do não-ser-intertextual - e, nesse caso, o discurso se mostra como urna história de ação e suspense (seu ser), sem grandes atributos - podendo passar pelo parecer até o ser-intertextual, com sua variedade e complexidade interpretativas. Há uma distância entre as posições cognitivas do enunciador (onisciente), cnunciatários e actantes narrativos. A debreagem instaura, nesse caso, um actante observador implícito, que assume as posições de sujeito tímico e sujeito cognitivo.

\section{A hipérbole e a ironia}

$\mathrm{O}$ processo intertextual recorrente torna o discurso todo um intertexto, valorizando a dimensão cognitiva do discurso. Essa dimensão manifesta-se, sobretudo, através do espaço discursivo e das figuras de

\footnotetext{
4. As figuras do plano do conteúdo misturam-se às do plano da expressão do sistema semi-simbólico de tal forma que a exigüidade deste texto não permite organizá-las adequadamente.
} 
conteúdo c expressão (espaço está sendo usado no seu sentido restrito, definido por suas propriedades visuais, em relação a seus usuários):

a) correlação pragmático-cognitiva correspondente à categoria semântica que nos permite classificar a figuração, não só como icônica, mas como intertextual c hiperbólica. Por exemplo, na seqüência locada na Igreja Católica (espaço do bem) Eliot Ncss c Malonc falam ate' dc juramento de sangue ("irmãos de sangue" (sic)), para lutarem contra o mal, a máfia, remetendo ao gênero "de gângster";

b) correlação pragmático-cognitiva correspondente às categorias plásticas que nos permitem classificar as figuras semi-simbólicas como intertextuais c hiperbólicas. Por exemplo, todos os recursos plásticos do noir, remetendo ao mal, o hotel suntuoso em que Al Capone mora, mostrado com recursos de enquadramentos, angulações e movimentos de câmera exagerados, remetendo ao poder do chefe dos gângsters, assim como na Estação, os exageros de angulação, movimento, montagem (mais de 60 cortes em 60s!), remetendo à famosa seqüência da escadaria dc Odessa dc Eisenstein ${ }^{5}$ c até a Hitchcock, com seus 70 planos $\mathrm{cm} 45 \mathrm{~s}$, cm Psicose

O actante observador exerce sua atividade cognitiva em relação à intertextualidade, entre outros recursos, pelo fazer persuasivo/ interpretativo simultâneo:

a) o persuasivo, através de um jogo contínuo de demonstrações, principalmente não-verbalizadas, icônicas, espaciais c ressemantizadas através da hipérbolc e da ironia;

b) o interpretativo, explorando discursos anteriores, considerados como referenciais, através da intertextualidade marcada por traços diferenciais, principalmente graças ao exagero c à ironia.

5. O EncouraçaJo Potemkin (1925), com direção de Sergei Eisenstein, mostra, numa escadaria da cidade de Odessa. a luta entre os marinheiros revoltosos que são mortos pelas tropas czaristas. 6. Na famosa seqüência do assassinato no chuveiro. 
o fazer-interpretativo de "os intocáveis"

0 modo de presença implícita do observador se mostra através de figuras isotópicas, principalmente ligadas às oposições temáticas profundas - o bem/o mal -, e marcadas pela hipérbole e pela ironia que a superpõe, que são dispositivos cognitivos que ajudam a desvendar a "verdade discursiva"'l Esses recursos que o intertexto sinaliza, durante todo o discurso, tornam-no paródico. A manipulação que era da ordem do secreto (ser vs. não-parecer), pelo paródico, desvenda a sua verdade (ser vs. parecer), num jogo enunciativo previsto para essa competência: identificar o intertexto, a hipérbole, a ironia.

A ironia tem como referência normas e valores que os participantes do discurso devem possuir, assim como um saber-fazer interpretativo idênticos. Desse modo, a ironia exerce a função de aproximar, congregar, os que detêm o saber c, concomitantemente, os separa, elitiza, em relação aos que não o detêm (BRANDT, 1986).

Além disso, nesse filme, ao modo do parecer, os recursos do exagero e paródia soam como se o sujeito da enunciação tratasse de desqualificar sua competência e performance (fazer produtor e manipulador), construindo efeitos de não-verdadeiro, não-verossímil - numa espécie de auto-ironia -, para que o eco dessa mesma ironia desvende a verdade (o ser discursivo) ${ }^{8}$

Como vimos, em Os Intocáveis, a transmissão do saber, de uma instância da enunciacão a outra, vem da instalação no interior do discurso de diferentes tipos de simulacros c dispositivos cognitivos. Esse programa cognitivo complexo empresta ao conjunto discursivo diversos estatutos veridictórios, entre eles o de que toda a sua estratégia é sustentada pela forma tcmático-narrativa do saber sobre a história do cinema e homenagear seus grandes diretores, como projeto discursivo e objeto-valor principal visado.

\footnotetext{
7. Notas de aula de pós-graduação da disciplina "Semiótica Discursiva" ministrada por E. Landovvski. São Paulo, PUC/USP, set. a nov, de 1994.

8. Notas de aula de pós-graduação da disciplina "Semiótica Discursiva" ministrada por E. Landowski. São Paulo, PUC/USP. set. a nov. de 1994.
} 


\section{Edith Lopes Modesto}

\section{Ficha Técnica}

Os Intocáveis (The Untouchables) - EUA, 1987

Direção: Brian DePalma.

Roteiro: David Mamet.

Fotografia: Stephien H. Burum.

Música: Ennio Morricone.

Elenco: Kevin Costner (Eliot Ness),

Sean Connery (Jimmy Malone),

Robert De Niro (A1 Capone),

Charles Martin Smith (Oscar Wallace),

Andy Garcia (George Stone),

Bill Drago (Frank Nitti),

Patricia Clarkson (Catherine). 


\section{Bibliografia}

BALOGH, A. M. (1987). Reflexões sobre Intertextualidadc em alguns Textos Fílmicos Contemporâneos. In: OLIVEIRA, Ana Cláudia e SANTAELLA, Lúcia (org.). Semiótica cia Comunicação e outras Ciências. Sào Paulo, EDUC.

BRANDT, A.P. (1986). Ironie. In: GREIMAS, A. J. c COURTÉS, J. Sémiotique. Dictionnaire Raisonné de ia Théorie du Langage IL Paris, Hachette.

BUCCI, E. (1991). Os Intocáveis. In: LABAKI, Amir (org.). O Cinema dos Anos 80. São Paulo, Brasiliensc.

FONTANille, J. (1986). Débrayage. In: GREIMAS, A. J. e COURTÉS, J. Sémiotique. Dictionnaire Raisonné de la Théorie du Langage II. Paris, Hachette.

GREIMAS, A. J. (1970). Du Sens. Paris, Seuil.

GREIMAS, A. J. c COURTÉS, J. s/d. Dicionário de Semiótica. São Paulo, Cultrix.

LANDOWSKI, E. (1992). A Sociedade Refletida. São Paulo, EDUC/ PONTES.

PATTE, D. (1986). Discursivisation. In: GREIMAS, A. J e COURTÉS, J. Sémiotique. Dictionnaire Raisonné de la Théorie du Langage IL Paris, Hachette.

RUPRECHT. (1986). Intertcxtualitc. In: GREIMAS, A. J. e COURTÉS, J. Sémiotique. Dictionnaire Raisonné de la Théorie du Langage IL Paris, Hachette. 